\section{Partial trisomy 22 in a liveborn resulting from a rearrangement between chromosomes 6 and 22}

EDITOR-We report on a case with an apparent duplication of $22 \mathrm{q}$ with an initial karyotype of 46,XY,add(6)(p24).ish $\operatorname{der}(6)$ (6qter $\rightarrow 6 \mathrm{p} 24:: 22 \mathrm{q} 11 \rightarrow 22 \mathrm{qter}$ ) (wcp6+,wcp22+).

To our knowledge this is the first report of such an association. We have attempted to characterise the exact regions of duplication using fluorescence in situ hybridisation (FISH) techniques and confirmed that the case is indeed not deleted for chromosome 6 and is only partially trisomic for $22 \mathrm{q}$, thus allowing a more detailed genotype-phenotype correlation than previous studies.

The majority of reports of duplication of chromosome 22 involve the proximal region on 22q. The most common cause of trisomy or tetrasomy of proximal $22 \mathrm{q}$ is a de novo supernumerary bisatellited marker chromosome derived from inverted duplication of $22 p$ and $22 q 11$. These supernumerary marker chromosomes have been associated with the cat eye syndrome (CES). ${ }^{1}$ In contrast, duplications of the distal part of the chromosome $22 \mathrm{q}$ region that arise de novo are relatively rare with only eight cases reported so far. $^{2-9}$ A clinical picture of the distal $22 \mathrm{q}$ duplication syndrome has emerged from this limited number of cases comprising growth retardation, shortened life span, congenital heart defects, hypertelorism, narrow palpebral fissures, small nose with anteverted nares, small thorax with hypoplastic nipples, muscular hypotonia, feeding difficulties associated with failure to thrive, and anomalies of the external genitalia in males. ${ }^{59}$

The boy was born at 39 weeks after an uneventful pregnancy to healthy, non-consanguineous, 33 year old parents. It was the second pregnancy; the first pregnancy was spontaneously aborted at 6 weeks' gestation. Family history was normal. Clinical examination at birth showed a proportionately small infant; weight was $1500 \mathrm{~g}(-4.5 \mathrm{SD})$, length $39 \mathrm{~cm}$ (-5.9 SD), head circumference (OFC) $28.3 \mathrm{~cm}$ $(-3.7 \mathrm{SD})$, and chest circumference $25.3 \mathrm{~cm}(-4.1 \mathrm{SD})$. $\mathrm{He}$ had cyanosis because of persistent fetal circulation, but congenital heart anomaly was not present. He had a round face, broad forehead, hypertelorism (not measured), low nasal bridge, depressed nasal tip, left unilateral cleft lip and cleft palate, low set and malformed ears, short neck, and low posterior hairline. There was no facial asymmetry. Hearing tests showed mild loss in both ears. Other anomalies included imperforate anus (ultrasonographic examination of the abdomen showed normal internal organs) and bilateral talipes.

Physical examination at 3 years 7 months showed poor weight gain, $9.36 \mathrm{~kg}(-3.1 \mathrm{SD})$, height $81.2 \mathrm{~cm}(-4.3 \mathrm{SD})$, and head circumference $42.8 \mathrm{~cm}(-4.1 \mathrm{SD})$. The patient had bilateral mild sensorineural deafness, 40-50 dB. Ophthalmological examination was performed and showed hypermetropic astigmatism and external squint. The optic field was normal. He showed moderate delay in psychomotor and growth retardation. He was able to control his head at the age of 6 months, sit independently at 1 year, and was able to walk without support at the age of 3 years 8 months. At 3 years he had no meaningful speech. The parents had apparently normal karyotypes. At this stage his molecular cytogenetic karyotype was 46,XY,add(6)(p24).ish der (6) (6qter $\rightarrow$ 6p 24:: 22q11 $\rightarrow$ 22qter) (wcp6+,wcp22+).

Cells were provided as an EBV transformed lymphoblast cell line. They were cultured at $37^{\circ} \mathrm{C}$ with $5 \% \mathrm{CO}_{2}$ in RPMI 1640 medium containing $4 \mathrm{mmol} / \mathrm{l}$ L-glutamine, $10 \%$ FCS, $2 \%$ penicillin and streptomycin. Metaphase chromosome spreads were prepared using standard techniques. Briefly, actively growing cells were treated with thymidine at $280 \mu \mathrm{g} / \mathrm{ml}$ for approximately 18 hours. They were then washed in fresh medium and allowed to grow for five hours after which they were treated with colcemid solution for 15 minutes and then resuspended in $75 \mathrm{mmol} / \mathrm{l}$ $\mathrm{KCl}$ before being finally fixed in 3:1 methanol:acetic acid. The preparation was then used for FISH experiments.

Cosmid, YAC (total yeast DNA including YAC), PAC, and BAC DNA was prepared by standard techniques. ${ }^{10}$ All clones were labelled with biotin-14-dATP or digoxigenin-

Table 1 Results of FISH on patient using 28 clones from 6p21.2-6p25.3 and 18 clones from 22q11.2-q13.32. All clones produced hybridisation signals on the normal chromosomes. Markers contained within each particular chromosome 6 clone are shown as landmarks for mapping and orientation purposes. The physical distances from the centromere of the chromosome 22 probes are taken from the Sanger Centre data (see materials and methods). The probes in both sections are ordered from $22 q$ telomere (top) to centromere (bottom)

\begin{tabular}{|c|c|c|c|}
\hline Chromosome location & Probe & $\begin{array}{l}\text { This case } 6 p \\
\text { (der) }\end{array}$ & $\begin{array}{l}\text { Distance (22cen) } \\
\text { markers }(6 p)\end{array}$ \\
\hline $22 \mathrm{q} 13.31-13.32$ & bk722'e9 & + & $33.3 \mathrm{Mb}$ \\
\hline $22 \mathrm{q}(\mathrm{NV})$ & $\mathrm{dJ} 127 \mathrm{~b} 20$ & + & $29 \mathrm{Mb}$ \\
\hline $22 \mathrm{q} 13.1-13.2$ & bk397c4 & + & $28.3 \mathrm{Mb}$ \\
\hline $22 \mathrm{q} 13.2$ & $\mathrm{dJ} 186 \mathrm{O} 1$ & + & $25.9 \mathrm{Mb}$ \\
\hline $22 \mathrm{q} 13.1$ & $\mathrm{bk} 229 \mathrm{a} 8$ & + & $24.46 \mathrm{Mb}$ \\
\hline $22 \mathrm{q}(\mathrm{NV})$ & $\mathrm{dJ} 124 \mathrm{O} 7$ & - & $21.8 \mathrm{Mb}$ \\
\hline $22 \mathrm{q} 12.3-\mathrm{q} 13.1$ & bk390b3 & - & $21.3 \mathrm{Mb}$ \\
\hline $22 \mathrm{q} 12.3$ & $\mathrm{bk} 212 \mathrm{a} 12$ & - & $19.98 \mathrm{Mb}$ \\
\hline $22 \mathrm{q}(\mathrm{NV})$ & dJ78b3 & - & $19.9 \mathrm{Mb}$ \\
\hline $22 \mathrm{q}(\mathrm{NV})$ & dJ $153 h 10$ & - & $19.2 \mathrm{Mb}$ \\
\hline $22 \mathrm{q}(\mathrm{NV})$ & dJ28811 & - & $18.7 \mathrm{Mb}$ \\
\hline $22 \mathrm{q} 12.1-12.2$ & $\mathrm{dJ} 213 \mathrm{~F} 7$ & + & $16.2 \mathrm{Mb}$ \\
\hline $22 \mathrm{q} 12.1$ & bk99f11 & - & $15.2 \mathrm{Mb}$ \\
\hline $22 \mathrm{q}(\mathrm{NV})$ & dJ9016 & - & $11.2 \mathrm{Mb}$ \\
\hline $22 \mathrm{q} 11.23-\mathrm{q} 12.1$ & bk992d9 & - & $11 \mathrm{Mb}$ \\
\hline $22 \mathrm{q} 11.2$ & bk433f6 & - & $4.4 \mathrm{Mb}$ \\
\hline $22 \mathrm{q} 11.2$ & bk154h4 & - & $3.2 \mathrm{Mb}$ \\
\hline $22 \mathrm{q} 11.2$ & bk115f6 & - & $1.7 \mathrm{Mb}$ \\
\hline $6 \mathrm{p} 25.3$ & c6k23 & + & \\
\hline $6 \mathrm{p} 25$ & $947 \mathrm{~d} 4$ & + & D6S344 \\
\hline $6 \mathrm{p} 25$ & $954 \mathrm{~h} 10$ & + & GMDS \\
\hline $6 \mathrm{p} 25$ & $\mathrm{dJ} 36 \mathrm{i} 2$ & + & A339YD9 \\
\hline $6 \mathrm{p} 25$ & $878 \mathrm{~b} 10$ & + & D6S477 \\
\hline $6 \mathrm{p} 25 \mathrm{px}$ & $863 \mathrm{~b} 6$ & + & F13A \\
\hline $6 \mathrm{p} 25 \mathrm{px}$ & $938 \mathrm{~b} 10$ & + & PREB1 \\
\hline $6 \mathrm{p} 25 \mathrm{px}$ & 786h6 & + & D6S1640 \\
\hline $6 \mathrm{p} 25 \mathrm{px}$ & $963 \mathrm{~h} 4$ & + & BMP6 \\
\hline $6 \mathrm{p} 24.3$ & $848 \mathrm{c} 12$ & + & D6S410 \\
\hline $6 \mathrm{p} 24.3$ & $808 \mathrm{a} 10$ & + & \\
\hline $6 \mathrm{p} 24.3$ & dJ $103 \mathrm{~m} 22$ & + & \\
\hline $6 \mathrm{p} 24.3$ & bk3J9 & + & stSG11165 \\
\hline $6 \mathrm{p} 24.3$ & dJ359113 & + & \\
\hline $6 \mathrm{p} 24.3$ & dJ108c15 & + & stSG11171 \\
\hline $6 \mathrm{p} 24.3$ & dJ167k8 & + & stSG11171 \\
\hline $6 \mathrm{p} 24.3$ & dJ110p13 & + & stSG11216 \\
\hline $6 \mathrm{p} 24.3$ & dJ $135 \mathrm{k} 15$ & + & stSG11216 \\
\hline $6 \mathrm{p} 24.3$ & dJ133h 11 & + & \\
\hline $6 \mathrm{p} 24.3$ & $886 \mathrm{c} 1$ & + & AP-2 \\
\hline $6 \mathrm{p} 24.3$ & $753 \mathrm{a} 9$ & + & \\
\hline $6 \mathrm{p} 24.3$ & $436 \mathrm{~h} 5$ & + & \\
\hline $6 \mathrm{p} 24.2$ & $938 \mathrm{~d} 8$ & + & AP-2 \\
\hline $6 \mathrm{p} 24.1$ & $915 \mathrm{e}^{\prime} 8$ & + & GCNT2 \\
\hline $6 \mathrm{p} 24.1 \mathrm{px}$ & $844 \mathrm{~h} 3$ & + & ZNF40 \\
\hline $6 \mathrm{p} 24.1 \mathrm{px}$ & $886 \mathrm{a} 2$ & + & D6S429 \\
\hline $6 \mathrm{p} 23$ & $912 \mathrm{~g} 9$ & + & \\
\hline $6 \mathrm{p} 21.2$ & bk12115 & + & \\
\hline
\end{tabular}

$+=$ presence and $-=$ absence of a hybridisation signal on the der (6)

$\mathrm{c}=$ cosmids $, \mathrm{dJ}=\mathrm{PACS}, \mathrm{bk}=\mathrm{BACS}$, those without a prefix are YAC clones, $\mathrm{NV}$ $=$ not verified. 
11-dUTP by nick translation (Bio-Nick Labeling System or Nick Translation System, respectively, BRL Life Technologies, USA). In situ hybridisation was performed as described previously. ${ }^{10}$ In total, 17 YAC, 16 PAC, 12 BAC clones, and one cosmid were used, of which the chromosome 6 clones had been previously FISH mapped to defined locations on $6 \mathrm{p}$ by us, ${ }^{11}$ while the chromosome 22 clones were part of the BAC clone set generated by Dr
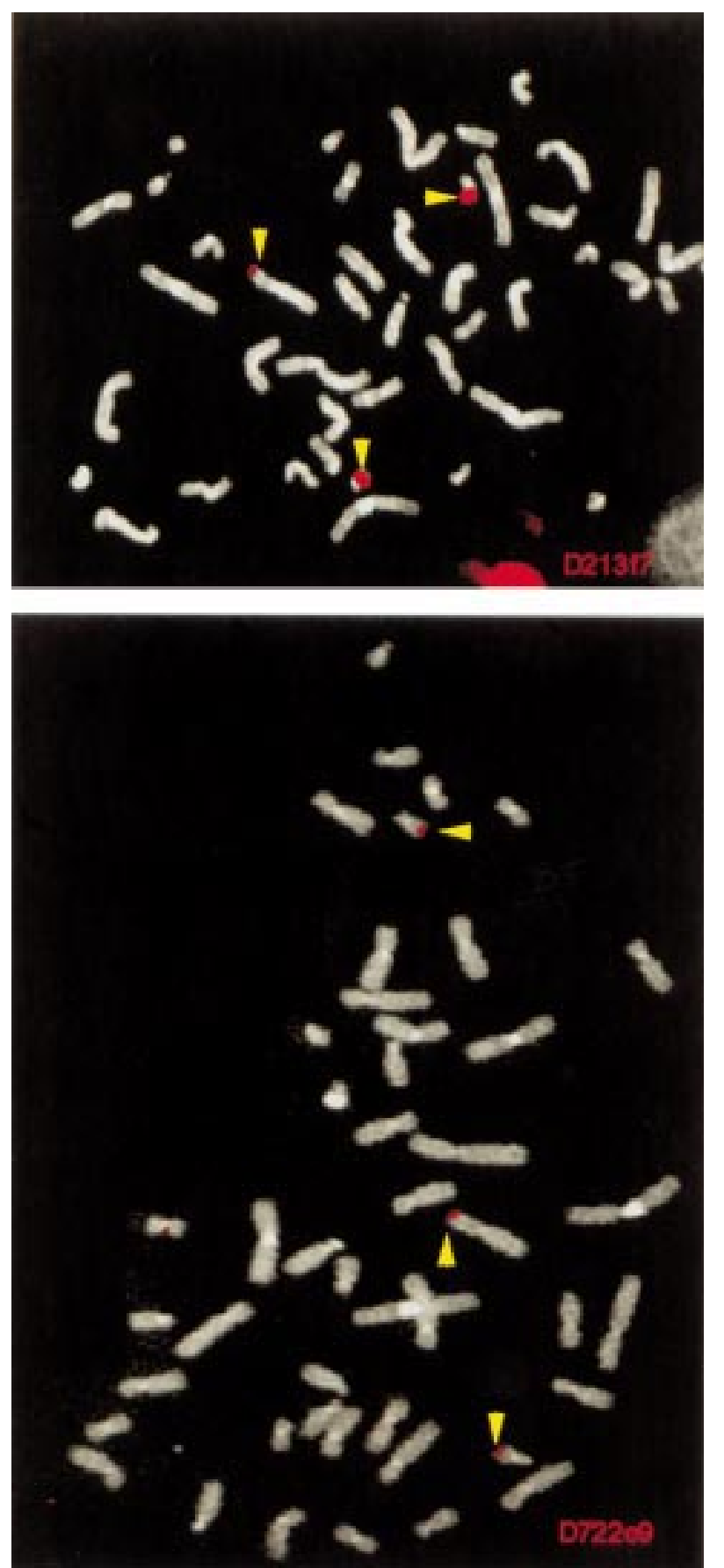

Figure 1 Examples of the results of in situ hybridisation on metaphase chromosomes of the proband. PAC clones from the q region of chromosome 22 are selected for presentation. (Top) An in situ hybridisation result using clone dF213f7 labelled with digoxigenin and detected using tetramethyl rhodamine isothiocyanate. $G$ banding is enhanced during image analysis. Signals show the proband to be trisomic for the proximal region of chromosome 22 (22q12.1), as indicated by arrowheads. (Bottom) In situ hybridisation result using df722e9 labelled and detected as df213f7. The clone produced hybridisation signals on both chromosomes 22 and an additional signal on der(6), indicating the case also to be trisomic for the distal region of the $22 q$ arm (qter).
Nigel Carter at the Sanger Centre (http://www. sanger.ac.uk/HGP/Cytogenetics/Bacset.shtml) or contained physically mapped genetic markers (http:// webace.sanger.ac.uk/cgi-bin/ace/simple/22ace) (table 1). The exact position of the chromosome 22 clones was retrospectively verified by the availability of the chromosome 22 sequence ${ }^{12}$ during the manuscript revision process (table 1).

Cytogenetic analysis of the case showed an abnormal short arm of one chromosome 6 carrying a deletion. Further FISH analysis was undertaken with 28 well characterised probes that covered the $6 \mathrm{p} 24-\mathrm{pter}$ region and a probe each for $6 \mathrm{p} 23$ and $6 \mathrm{p} 21.2$. All the probes hybridised with equal intensity to both normal and derivative chromosomes 6 , indicating that the telomeric part of chromosome 6 is intact (table 1).

FISH with a whole chromosome 22 paint gave positive hybridisation signals along the entire length of both the normal chromosomes 22 as well as on the end of the derivative $6 \mathrm{p}$ arm. In order to establish which part of chromosome 22 is present in the derivative chromosome 6 , we used 18 PAC and BAC clones with defined chromosomal locations or containing markers from the genetic map or both (table 1).

FISH with clone 213f7 located in 22q12.1-12.2 gave an additional signal on the end of the derivative $6 \mathrm{p}$. Clones 115f6, 154h4, 433f6 (located in 22q11.2), 992d9 (located in 22q11.23), 99f11 (located in 22q12.1), 212a12, and $390 \mathrm{~b} 3$ (located in 22q12.3-13.1) showed no additional signals on the short arm of chromosome 6 , whereas clones $229 \mathrm{a} 8,394 \mathrm{c} 4$, and $722 \mathrm{e} 9$ located in $22 \mathrm{q} 13.1 \rightarrow 22 \mathrm{q} 13.32$ gave additional signals on the derivative chromosome (table 1). We observed the following order of hybridisation signals on the derivative chromosome: bk121L5 (6p21.2) c6k23 (6p25.3) - dJ213f7 (22q12.1-12.2) - bk722e9 (22q13.31-13.32). Representative examples of results are shown in fig 1 .

In conclusion, we have established that the derivative chromosome 6 is not deleted for any region of $6 p$ at least up to the subtelomeric marker D6S344 (the distance between cosmid $6 \mathrm{k} 23$ and D6S344 is not known). The rearranged duplicated chromosome 22 forms the telomeric portion of the derivative chromosome 6 (fig 2A). The duplicated regions include a small segment of the 22q12.1-q12.2 region between clones bk99f11 (not duplicated) and bk28811 (not duplicated) (table 1, fig 2B). We can determine the maximum size of this duplicated segment, as detected by PAC dJ213F7 containing the marker D22S1175, from the available chromosome 22 data (http://webace.sanger.ac.uk/cgi-bin/ace/simple/22ace) as being $3.5 \mathrm{Mb}$. The $22 \mathrm{q} 13$ duplication starts from a region between the markers D22S344 (bk390b3, not duplicated) and D22S279 (bk229a8, duplicated) within q13.1 and extends through the rest of the long arm, covering a maximum of $14 \mathrm{Mb}$ (table 1 , fig2B).

Our results refined the cytogenetic diagnosis and enabled us to specify a new karyotype for the case (fig $2 \mathrm{~A})$ : $46, \mathrm{XY}, \operatorname{der}(6)$ (6qter $\rightarrow 6 \mathrm{p} 24:: 22 \mathrm{q} 11 \rightarrow 22 \mathrm{qter})$.ish $\operatorname{der}(6)$ (6qter $\rightarrow$ 6p25 :: 22q12.1 $\rightarrow$ 22q12.2 :: 22q13.1 $\rightarrow$ 22qter) (bk12115+, 912g9+, 886a2+, 844h3+, 915e8+, 938d8+, 436h5t, 753a9t, 886c1t, dJ133h11t, dJ135k15+, dJ110p13+, dJ167k8+, dJ108c15+, dJ359113+, bk3J9+, dJ103m22+, 808a10+, 848c12+, 963h4t, 786h6+, $938 \mathrm{~b} 10+, 863 \mathrm{~b} 6+, 878 \mathrm{~b} 10+, \mathrm{dJ} 36 \mathrm{i} 2+, 954 \mathrm{~h} 10+, 947 \mathrm{~d} 4+$, c6k23+, bk722e9+, dJ127b20+, bk397c4+, dJ18601+, bk229a8+, dJ12407, bk212a12-, bk390b3-, dJ78b3-, dJ153h10-, dJ28811-, dJ213F7+, bk99f11-, dJ9016-, bk992d9-, bk433f6-, bk154h4-, bk115f6-).

The FISH with well defined probes confirmed that this case is partially trisomic for 22q12.1-12.2 and 22q13.1- 
A

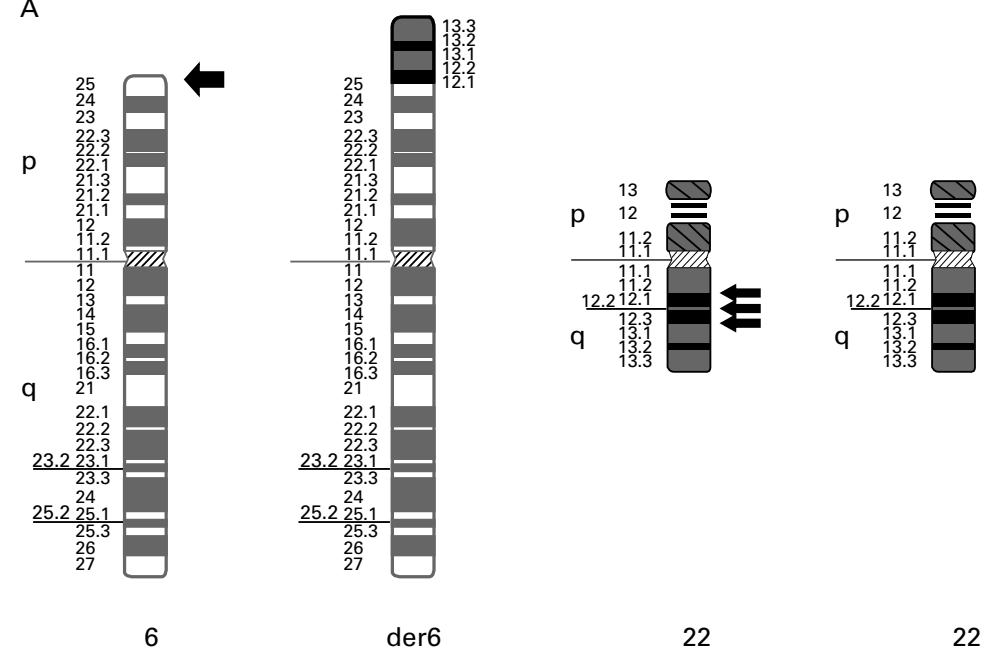

B

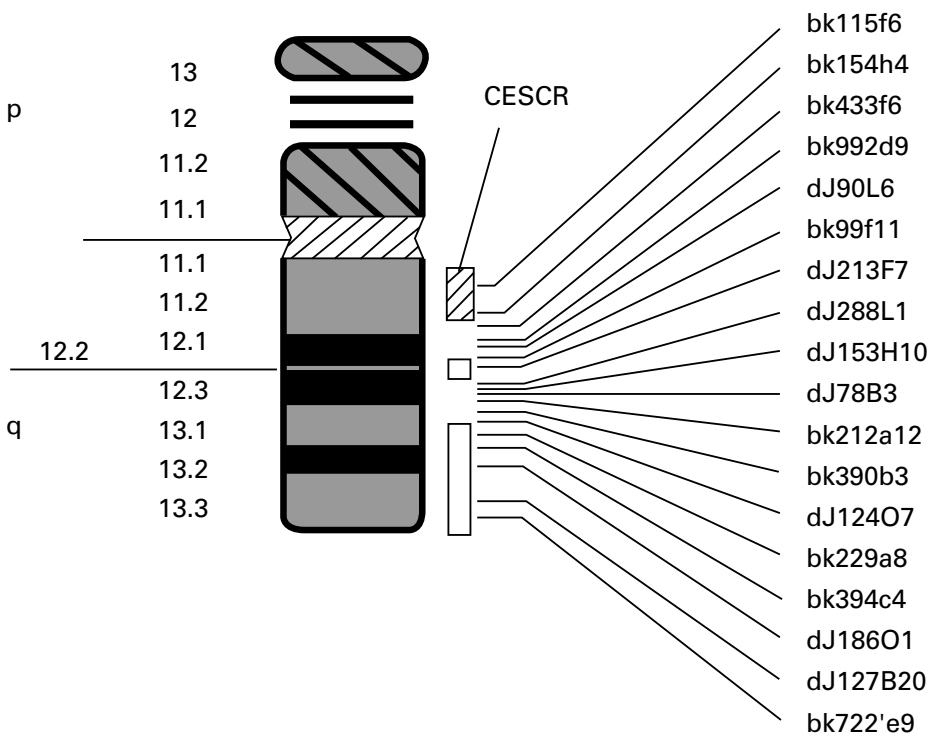

Figure 2 (A) Human chromosome ideogram (G banding) presented to characterise the nature of the abnormality detected in this case. The arrows indicate the position of the breakpoints that must have occurred de novo on the additional chromosome 22 before interacting on the end of the derivative chromosome 6 in the order as observed with FISH image analysis. (B) Ideogram of human chromosome 22 showing the position of the probes used in relation to the CES region (hatched box) and the distinct duplicated regions in this study (open box).

qter without any deletion of $6 \mathrm{p}$. This anomaly is not a result of malsegregation states since both parents have a normal karyotype.

Although the chromosomal rearrangement of our case is unique, the most cytogenetically similar case published to date is the one by Wieczorek et al. ${ }^{9}$ Although Wieczorek et $a l^{9}$ did not perform a detailed FISH analysis, comparison of the markers contained in the probes used show that the reported $22 \mathrm{q} 13$ duplication has occurred distal to the marker D22S102. The breakpoint was not identified since the next marker used in their study is close to the telomere $\left(\mathrm{ARSA}^{13}\right)$. The breakpoint in our case occurred proximal to D22S279 and distal to D22S344 and D22S156 (and therefore also distal to D22S102) within a $2 \mathrm{cM}$ interval.

The phenotypes are comparable, namely protuding forehead, hypertelorism, broad nasal bridge, orofacial clefting, low set ears, growth retardation, and psychomoter retardation. In contrast to their case, our case also had imperforate anus, hearing loss, and talipes. Our results clearly reinforce the findings associated with distal $22 \mathrm{q}$ duplication and the correlation of the phenotypic characteristics with the duplication of 22q13.1-qter is now confirmed by molecular techniques. Table 2 summarises the phenotypic comparison between this case, Wieczorek et $a l,{ }^{9}$ and the review of previous cases in Wiezcorek et al. ${ }^{9}$

Anal atresia has rarely been observed in cases presenting with proximal or distal interstitial duplications and it is often associated with many other malformations. The anomaly is mainly associated with CES, derivative (22) syndrome, or complete trisomy. ${ }^{14-17}$ The CES critical region has been defined as an approximately $2 \mathrm{Mb}$ segment between the centromere and marker D22S $57 .{ }^{18} \mathrm{~A}$ part of this region has been cloned ${ }^{19}$ and two of the BAC clones used in this study (bk115f6 and bk154h4) are also part of the contig presented by Johnson et al, ${ }^{19}$ thus enabling a direct comparison with their data. The proximal breakpoint of the proximal duplication in the case described here is approximately $9 \mathrm{Mb}$ distal to the distal breakpoint cluster identified in CES patients. ${ }^{20}$ Therefore, unless an additional undetected part of chromosome 22 is duplicated in 
Table 2 Major clinical features in trisomy 22q13-qter. The table includes the summary and case as in Wieczorek et al compared to this case

\begin{tabular}{llll}
\hline & $\begin{array}{l}\text { Wieczorek } \\
\text { et al }\end{array}$ & This case & $\begin{array}{l}\text { dup22 } \\
(q 13 \rightarrow \text { ter })\end{array}$ \\
\hline Sex & F & M & \\
Small for gestational age & + & + & $7 / 7$ \\
Muscular hypotonia & + & - & $3 / 4$ \\
Mental retardation & + & Mild & $3 / 3$ \\
Feeding difficulties & + & NR & $3 / 3$ \\
Microcephaly & + & + & $4 / 7$ \\
Congenital hydrocephalus & - & - & $4 / 5$ \\
Arrhinencephaly & - & - & $1 / 4$ \\
Hypertelorism & + & + & $4 / 4$ \\
Narrow palpebral fissures & + & - & $4 / 4$ \\
Small nose with anteverted nares & + & - & $4 / 4$ \\
Thin upper lip & NR & - & $3 / 3$ \\
Cleft palate & + & + & $5 / 8$ \\
Retro/micrognathia & + & - & $5 / 6$ \\
Dysplastic ears & + & + & $4 / 4$ \\
Low set ears & + & + & $5 / 6$ \\
Short neck & + & + & $4 / 4$ \\
Small thorax with hypoplastic nipples & + & - & $4 / 4$ \\
Congenital heart defect & + & - & $5 / 7$ \\
Genital anomalies & $/$ & - & $3 / 3$ \\
Foot deformities & + & + & $4 / 4$ \\
Short feet & + & - & $2 / 2$ \\
Small hands & + & - & $1 / 2$ \\
Imperforate anus & - & + & - \\
Survival & Still alive & Still alive & 1 day-11 \\
& & $(3$ years $)$ & months \\
\hline & & & \\
\hline & & &
\end{tabular}

the $1.7 \mathrm{Mb}$ region between the centromere and bk115f6, we can conclude that the duplications identified in this case are unrelated to the CES critical region (fig 2B). Our case may be significant in that it proposes that overexpression of $22 \mathrm{q} 12.1 \rightarrow 22 \mathrm{q} 12.2$ distal to the regions associated with CES or of $22 \mathrm{q} 13$ may be involved in the pathogenesis of anal anomalies. Alternatively there could be a duplication of a small segment of $22 \mathrm{q} 11$ that lies between the PAC and BAC clones used and remains undetected or there is an undetected deletion of $6 \mathrm{p}$ near the telomere that may influence the phenotype. Position effects on the expression of genes within $6 \mathrm{p} 25$ are also a possibility. However, anal abnormalities are not part of the distal $6 p$ deletion syndrome. ${ }^{11}$ The breakpoints of our case are distributed on the $\mathrm{q}$ arm, the proximal breakpoints being near 22q12.1$22 \mathrm{q} 12.2$ and the distal breakpoint in 22q13.1. There seems to be a correlation between the position of the common aphidicolin inducible fragile site found at $22 \mathrm{q} 12.2$ and our proximal breakpoints and the rare folate sensitive fragile site FRA22A, recognised at 22q13, with our distal breakpoint. ${ }^{21}$

We have shown by using individual clones that we were able to define clearly the nature of the anomaly and delineate and segregate the clinical presentations associated with specific segments. The conduct of similarly detailed studies will allow more precise comparisons between individual cases in the future.

We would like to thank the UK's HGMP-Resource Centre for providing PAC clones, Dr Ian Dunham (Sanger Centre) for providing BAC clones, and Dr Angela Davies and Dr Paul
MRC grant G9533412.
GHAZALA MIRZA* KIYOSHI IMAIZUMI JIANNIS RAGOUSSIS

${ }^{\star}$ Division of Medical and Molecular Genetics, Guy's Tower, The Guy's, King's College and St Thomas's Hospitals' Medical and Dental School, Guy's Hospital, London SE1 9RT, UK

† Division of Medical Genetics, Kanagawa Children's Medical Centre,

Kutsukawa 2-138-4, Minami-ku, Yokohama, Kanawaga, 232-8555

fapan

Correspondence to Dr Ragoussis, ioannis.ragoussis@kcl.ac.uk

1 McDermid HE, Duncan AMV, Brasch KR, Holden JJA, Magenis E, Sheeny R, Burn J, Kardon N, Noel B, Schinzel A, Teshima I, White BN. Characterization of the supernumerary chromosome in cat eye syndrome. Science 1986;232:646-8

2 Fryns JP, Backer D, Lemli L, Pedersen JC, Berghe VD. Partial duplication of the long arm of chromosome $22(22 \mathrm{q} 13)$ with complete 22 trisomy phenotype. Acta Paediatr Belg 1980;33:125-7.

3 Cantu JM, Hernandez A, Vaca G, Plasencia L, Martinez-Basalo C, Ibarra B, Rivera $\mathrm{H}$. Trisomy $22 \mathrm{q} 12$ leads to qter: "aneusomie de recombinaison" of a pericentric inversion. Ann Genet 1981;24:37-40.

4 Fujimoto A, Wilson MG, Towner JW. Duplication of the segment $\mathrm{q} 12.2 \rightarrow$ qter of chromosome 22 due to paternal inversion 2 (p13q12.2). Hum Genet 1983;63:82-4.

5 Rivera H, Garcia-Esquivel L, Romo MG, Perez-Garcia G, Martinez Y, Martinez R. The $22 \mathrm{q}$ distal trisomy syndrome in a recombinant child. Ann Genet 1988;31:47-9.

6 Johnson MP, Greb A, Goyert, Drugan A, Qureshi F, Sacks AJ, Evans MI. Midtrimester diagnosis and anomalies in the $\operatorname{dup}(22 \mathrm{q})$ syndrome: correlation of aneuploidy with low maternal serum alpha-fetoprotein and oligohydramnios. Am f Med Genet 1990;36:94-6.

7 Stoll C, Medeiros P, Pecheur H, Schnebelen A. De novo trisomy 22 due to an extra 22q- chromosome. Ann Genet 1997;40:217-21.

8 Bendel RP, Baldinger S, Millard C, Arthur DC. Two succesive partial trisomies for opposite halves of chromosome 22 in a mother with a balanced translocation. F Med Genet 1982;19:313.

9 Wieczorek D, Holtvogt J, Thonig S, Gillessen-Kaesbach G. A female patient with partial duplication 22 (q13 $\rightarrow$ qter). Clin Dysmorphol 1998;7:289-94.

10 Davies AF, Olavesen MG, Stephens RJ, Davidson R, Delneste D, Regemorter N, Vamos E, Flinter F, Abusaad I, Ragoussis J. A detailed investigation of two cases exhibiting characteristics of the $6 \mathrm{p}$ deletion syninvestigation of two cases exhibiting
drome. Hum Genet 1996;98:454-9.

11 Davies AF, Mirza G, Sekhon G, Turnpenny P, Leroy F, Speleman F, Law C, van Regemorter N, Vamos E, Flinter F, Ragoussis J. Delineation of two distinct $6 \mathrm{p}$ deletion syndromes. Hum Genet 1999;104:64-72.

12 Dunham I, Shimizu N, Roe BA, Chissoe S, Hunt AR, Collins JE, Bruskiewich R, Beare DM, Clamp M, Smink LJ, Ainscough R, Almeida JP, Babbage A, Bagguley C, Bailey J, Barlow K, Bates KN, Beasley O, Bird CP, Blakey S, Bridgeman AM, Buck D, Burgess J, Burrill WD, O'Brien KP.The DNA sequence of human chromosome 22. Nature 1999;402:489-95.

13 Collins JE, Cole CG, Smink LJ, Garrett CL, Leversha MA, Soderlund CA, Maslen GL, Everett LA, Rice KM, Coffey AJ, Gregory SG, Gwilliam R, Dunham A, Davies AF, Hassock S, Todd CM, Lehrach H, Hulsebos TJM, Weissenbach J, Morrow B, Kucherlapati RS, Wadey R, Scambler PJ, Kim ley DR Dunham I. A high-density YAC contig map of human chromosome 22. Nature 1995;377:367-79.

14 Schinzel A, Schmid W, Fraccaro M, Tiepolo L, Zuffardi O, Opitz JM, Lindsten J, Zetterqvist P, Enell H, Baccichetti C, Tenconi R, Pagon RA. The "cat eye syndrome": dicentric small marker chromosome probably derived from a No 22 (tetrasomy 22 pter -q11) associated with a characteristic phenotype. Hum Genet 1981;57:148-58.

15 Iselius L, Faxilius G. Trisomy 22 in a newborn girl with multiple malformations. Hereditas 1978;89:269-71.

16 Vioculesco I, Back E, Duncan AMV, Schwaibold H, Schempp W. Trisomy 22 in a newborn with multiple malformations. Hum Genet 1987;76:298301.

17 Fraccaro M, Lindsten J, Ford CE, Iselius L. The 11q;22q translocation: a European collaborative analysis of 43 cases. Hum Genet 1980;56:21-51.

18 Mears AJ, El-Shanti H, Murray JC, McDermid HE, Patil SR. Minute supernumerary ring chromosome 22 associated with cat eye syndrome: further delineation of the critical region. Am ₹ Hum Genet 1995;57:667-73.

19 Johnson A, Minoshima S, Asakawa S, Shimizu N, Shizuya H, Roe BA, McDermid HE. A 1.5-Mb contig within the cat eye syndrome critical region at human chromosome 22q11.2. Genomics 1999;57:306-9.

20 McTaggart KE, Budarf ML, Driscoll DA, Emanuel BS, Ferreira P, McDermid HE. Cat eye syndrome chromosome breakpoint clustering: identification of two intervals also associated with 22 q11 deletion syndrome breakpoints. Cytogenet Cell Genet 1998;81:222-8.

21 Sutherland GR. Chromosome fragile sites. GATA 1991;8:161-6. 